\title{
Case Report and Review of the Literature
}

\section{Cauda Equina Syndrome after Sequestered Disc Herniation Migrating to the Dorsal Epidural Space: Case Report and Review of the Literature}

\author{
Abdullah Alshammari ${ }^{* \#, ~ R o d r i g o ~ N a v a r r o-R a m i r e z ", ~ S u s a n ~ G e ~ a n d ~ M i c h a e l ~ W e b e r ~}$ \\ Division of Orthopaedics Surgery, McGill University Health Centre, Montreal, Canada \\ ${ }^{\#}$ Contributed equally
}

\section{ARTICLE INFO}

Article history:

Received: 8 June, 2020

Accepted: 18 June, 2020

Published: 25 June, 2020

Keywords:

Migrated disc

spine surgery

discectomy

facet joint cyst

\begin{abstract}
A B S T R A C T
Background: Posteriorly migrated epidural disc fragments (PMEDF) presenting with cauda equina syndrome are relatively common. These cases are sometimes inaccurately identified on MRI as; epidural tumors, abscesses, hematomas and or facet cysts. Proper description and identification are key to be able to provide effective and safe management. Currently we are presenting the case of a patient with cauda equina syndrome secondary to a posterior mass compression intraoperatively identified as a PMEDF.

Case Description: 45-years-old male presenting with insidious low back pain that progressed to urinary retention and bilateral foot drop. An MRI of the lumbar spine showed a posteriorly located epidural lesion. That appeared to be dependent on a left facet cyst. The patient was treated with a decompressive laminectomy and multiple disc fragments were identified under the ligamentum flavum and over the posterior epidural space.

Conclusion: Posterior epidural migration of a lumbar disc fragments (PEMLDF) are not a common presentation of intervertebral disc herniations and their differential diagnosis and treatment might require a different surgical approach; fusion vs decompression. PEMLDFs should be suspected on those patients presenting with sudden cauda equina syndrome and posteriorly located epidural lesions on MRI.
\end{abstract}

\section{Introduction}

A lumbar disc herniation is defined as the protrusion of the nucleus pulposus beyond the normal boundaries of the fibrous annular ring [1]. A lumbar disc most commonly herniates in two directions, posterolateral direction or central herniation (anterior epidural space). This occurs because it is limited by the presence of enforcing structures posterior to the disc, the posterior longitudinal ligament (PLL) and its related midline septum and lateral membranes [2]. As first reported by Lombardi in 1973, posterior epidural migration of a lumbar disc fragment (PEMLDF), the migration of disc materials that wrap around the thecal sac from anterior to the posterior epidural space, are a rare type of presentation [1, 3]. PEMLDFs present as a lesion in the posterior epidural space on magnetic resonance imaging (MRI), which can mimic different pathologies such as epidural tumors, hematomas, facet cysts and abscess, making the diagnosis and treatment challenging [4]. The clinical presentation of patients with PEMLDF can range from lower back pain, nerve root irritation, radiculopathy and surprisingly common cauda equina syndrome $[1,4]$. Here we present the case of a 45 -year-old male patient who presented with cauda equina syndrome, secondary to a PEMLDF that mimicked a lumbar facet joint cyst.

\section{Case Report}

A 45-year-old male presented with a two-week history of progressive lower back pain, radiating to both lower limbs and weakness, which started while working in his farm. He was first seen by a family physician who prescribed oral pain medication without improvement. The patient then returned after presenting 2 episodes of difficulty voiding. At arrival to the Emergency Department the patient presented no stool incontinence, nor saddle anaesthesia. There was no history of direct trauma, infection or cancer. On examination, the patient presented bilateral foot drop and was not able to dorsiflex both ankles and big toes against resistance. Reflexes were normal and upper motor signs were

*Correspondence to: Abdullah Alshammari, M.D., Division of Orthopaedics Surgery, McGill University Health Centre, Montreal, Canada; E-mail: dralshammari.abdullah@gmail.com 
negative. In addition, he presented numbness over the right anterior thigh in the distribution of L3 and left anterior and medial foot on the distribution of L4-L5.

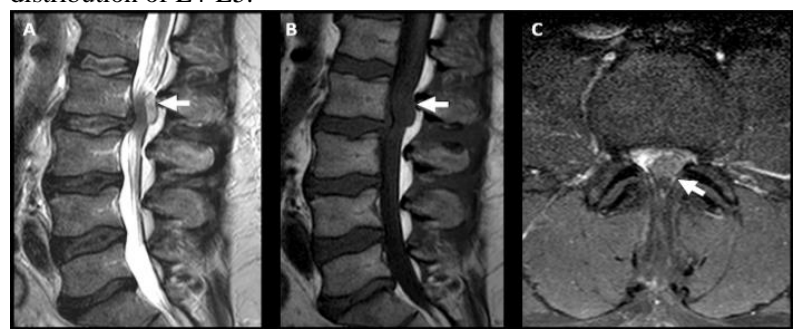

Figure 1: A) Preoperative sagittal MRI T2. B) Preoperative T1 sagittal MRI. C) Preoperative T2 axial MRI.

All laboratory tests retuned within normal parameters. MRI showed severe spinal stenosis and a posterior $\mathrm{T} 2$ hyperintense and $\mathrm{T} 1$ hypointense lesion at the L2-L3 level (Figure 1). Based on the clinical scenario, the patient was treated via a laminectomy of L2 vertebrae.
Immediately after the laminectomy and flavectomy was performed disc material instead of epidural fat was found. The material was located around the dura and followed to its annular defect origin. The postoperative period was uneventful with full recovery at one year follow up, Including bladder control, sensory and motor strength bilaterally.

\section{Discussion}

Posteriorly migrated epidural disc fragments (PMEDF) have been reported due to their unconventional clinical and radiological presentation (Table 1). Clinical symptoms include mechanical back pain, and radiculopathy or nerve root irritation after posterolateral disc bulging, compressing the exiting nerve root. Herniated PMEDF surprisingly are commonly present with cauda equina syndrome. Normally because the disc bulges posterolaterally surrounding and compressing the terminal spinal roots on a circumferential fashion at the lumbosacral level of origin [1].

Table 1: Summary of previously reported clinical and MRI findings of PMEDF.

\begin{tabular}{|c|c|c|c|c|}
\hline Article & Primary Symptoms & MRI findings & Treatment & Differential Diagnosis \\
\hline Hawkins J C et al. (2018) [1] & $\begin{array}{l}40 \mathrm{M} \text {, seven days of cauda } \\
\text { equina }\end{array}$ & $\begin{array}{l}\text { Left heterogeneous } \\
\text { hyperintense mass at L4-L5 }\end{array}$ & $\begin{array}{l}\text { decompression laminectomy } \\
\text { at L4-5 }\end{array}$ & Epidural tumor and abscess \\
\hline C.Y. Chen et al. (2006) [2] & $75 \mathrm{M}$, radiculopathy & $\begin{array}{l}\text { Right isointense mass with } \\
\text { rim enhancement at L2-L3 }\end{array}$ & $\begin{array}{l}\text { Decompression laminectomy } \\
\text { at L2-L3 }\end{array}$ & NA \\
\hline $\begin{array}{l}\text { Morito takano et al. (2017) } \\
\text { [3] }\end{array}$ & $\begin{array}{l}78 \mathrm{M} \text {, LBP, gait disturbance } \\
\text { and bilateral legs numbness }\end{array}$ & $\begin{array}{l}\text { Left ring Enhancing lesion } \\
\text { L3-L4 }\end{array}$ & $\begin{array}{l}\text { Decompression laminectomy } \\
\text { from L2-L4 }\end{array}$ & $\begin{array}{l}\text { Epidural Hematoma and } \\
\text { abscess }\end{array}$ \\
\hline Dosoglu M et al. (2001) [6] & $\begin{array}{l}47 \text { M, } 15 \text { days of cauda } \\
\text { equina }\end{array}$ & $\begin{array}{l}\text { Left ring Enhancing Lesion } \\
\text { L3-L4 }\end{array}$ & $\begin{array}{l}\text { decompression by fenestration } \\
\text { at L3-L4 }\end{array}$ & NA \\
\hline
\end{tabular}

Early recognition and management of PMEDF is crucial as it may be confused clinically and radiologically with other lesions in the posterior epidural space. These lesions may include abscess, cyst, hematoma, and tumor. Due to the non-specific finding in Magnetic resonance imaging (MRI), the diagnosis of PMEDF is more challenging. Identification of PMEDF over their differential diagnosis is important because normally tumors and facet cysts are treated different than hematomas, abscess or classic disc herniations, mainly the first group might be a candidate for fusion and the second will not [5]. The exclusion among differential diagnosis is sometimes time consuming and delays adequate treatment. To our knowledge only 8 cases have been reported until now as PMEDF $55 \%$ of patients with PMEDF present with cauda equina syndrome which makes early diagnosis of this condition critical because is well known that surgical treatment of cauda equina syndrome within 48 hours will improve the motor and sensory symptoms, in addition to bladder and rectal function $[1,5]$.

\section{Conclusion}

Patients with PMEDF have an unconventional clinical and radiological presentation and very commonly present with cauda equina syndrome. The accurate pre-operative diagnosis is key to decide the appropriate modality of treatment and if patients will be candidates for decompression alone and or fusion.

\section{REFERENCES}

1. Hawkins JC, Natkha VP, Seibly J (2018) Posterior Epidural Migration of a Lumbar Disc Herniation Causing Cauda Equina Syndrome: A Case Report. Cureus 10: e2739. [Crossref]

2. Chen CY, Yao MS, Chiu WT, Chen CL, Chan WP (2006) Posterior Epidural Migration of a Sequestrated Lumbar Disk Fragment MR Imaging Findings AJNR Am J Neuroradiol 27: 1592-1594. [Crossref]

3. Takano M, Hikata T, Nishimura S, Kamata M (2017) Discography aids definitive diagnosis of posterior epidural migration of lumbar disc fragments: case report and literature review. BMC Musculoskelet Disord 18: 151. [Crossref]

4. Haddadi K, Qazvini HR (2016) Posterior Epidural Migration of a Sequestrated Lumbar Disk Fragment Causing Cauda Equina Syndrome in an Old Patient: A Case Report. Clin Med Insights Case Rep 9: 3941. [Crossref]

5. Ahn UM, Ahn NU, Buchowski JM, Garrett ES, Sieber AN et al. (2000) Cauda Equina Syndrome Secondary to Lumbar Disc Herniation A Meta-Analysis of Surgical Outcomes. Spine (Phila Pa 1976) 25: 15151522. [Crossref]

6. Dösoğlu M, Is M, Gezen F, Ziyal MI (2001) Posterior epidural migration of a lumbar disc fragment causing cauda equina syndromeCase report and review of the relevant literature. Eur Spine J 10: 348351. [Crossref] 